\section{Experience with Hemodialysis Patients in the COVID-19 Pandemic in Sakarya, Turkey}

Sir,

The novel coronavirus disease 2019 (COVID-19) is an infectious disease that has been discovered recently. ${ }^{1}$ The severe acute respiratory syndrome coronavirus 2 (SARS-CoV-2) infection initially manifests as an acute respiratory tract disease with interstitial and alveolar pneumonia; however, it may affect multiple organs such as kidney, heart, digestive system, blood and nervous system. ${ }^{2}$

The infection which began in Wuhan, the Hubei Province of China, in December 2019 and has rapidly spread, has raised concerns since it has become a global pandemic. COVID-19 progresses with increased morbidity and mortality in patients with chronic illnesses. ${ }^{3}$ Moreover, this infection deserves a special assessment and action plan for dialysis patients, renal transplant patients, chronic renal disease patients and other nephrology patients. ${ }^{4}$

In public and private dialysis centres in the province of Sakarya, Turkey, 852 patients were treated and followed in the chronic hemodialysis programme. Since the outbreak of this disease and identification of the first case in Sakarya, Turkey, we, at the Department of Nephrology, contacted all dialysis centres in the province. As the patients were transported with a service system collectively across the province, we provided all drivers with digital thermometers, so that they could take each patient's temperature before they got into the bus. Subsequently, we examined symptoms, and if found the temperature $>38^{\circ} \mathrm{C}$, we referred them to our hospital via an ambulance. The same procedure was also followed at the entrance of all hemodialysiscentres.

When we received first cases, we made a separate room within the dialysis centre, for them. Then, we sent all our regular dialysis patients to other centres in order to prevent the healthy patients from encountering COVID-19 infected patients. Thus, we collected all symptomatic patients in single centre and protected othercentres.

All dialysis patients diagnosed with COVID-19 were hospitalised. They were treated with oseltamivir, hydroxychloroquine, and azithromycin. In addition, they all have had pulmonary CT scans (low dose).
In our clinic, seven patients are still being treated and followed; 38 patients have been discharged; however, they are still receiving dialysis treatment in our ambulatory centre. In Sakarya, six dialysis patients died from the COVID-19 infection.

Although, we are not sure what the future holds in this long-running process, we think that with this strategy, that we planned and executed, we can overcome this process with minimum loss of life.

\section{CONFLICT OF INTEREST:}

Authors declared no conflict of interest.

\section{AUTHORS' CONTRIBUTION:}

SS: Drafted the manuscript.

HD: Clinical follow-up.

AT: Data collection.

OK: Laboratory analysis.

\section{REFERENCES}

1. World Health Organization Official Website [Internet] Available from: http: //www.who.int.

2. Wang D, Hu B, Hu C, Zhu F, Liu X, Zhang J, et al. Clinical characteristics of 138 hospitalised patients with 2019 novel coronavirus-infected pneumonia in wuhan, China. JAMA 2020; 323(11):1061-9. doi: 10.1001/jama.2020.1585.

3. Huang C, Wang Y, Li X, Ren L, Zhao J, Hu Y, et al. Clinical features of patients infected with 2019 novel coronavirus in Wuhan, China. Lancet 2020; 395(10223): 497-506. doi: 10.1016/S0140-6736(20)30183-5.

4. Ikizler TA. COVID-19 and Dialysis Units: What Do We Know Now and What Should We Do? Am J Kidney Dis 2020; 76(1):1-3. doi: 10.1053/j.ajkd.2020.03.008.

Savaş Sipahi', Hamad Dheir ${ }^{1}$, Aysel Tocoglu ${ }^{1}$ and Oguz Karabay $^{2}$

${ }^{1}$ Department of Internal Medicine, Division of Nephrology, Sakarya University, Faculty of Medicine, Turkey

${ }^{2}$ Department of Infectious Diseases, Clinical Microbiology, Sakarya University, Faculty of Medicine, Turkey

Correspondence to: Dr. Savaş Sipahi, Department of Internal Medicine, Division of Nephrology, Sakarya University, Faculty of Medicine, Turkey

E-mail: ssipahi@sakarya.edu.tr

Received: June 08, 2020; Revised: August 21, 2020; Accepted: August 21, 2020

DOI: https://doi.org/10.29271/jcpsp.2020.JCPSPCR.CR138 